This item was submitted to Loughborough's Research Repository by the author.

Items in Figshare are protected by copyright, with all rights reserved, unless otherwise indicated.

\title{
Improving perceptions of value to teaching and research staff: the next challenge for academic libraries
}

PLEASE CITE THE PUBLISHED VERSION

http://dx.doi.org/10.1177/0961000613477678

\section{PUBLISHER}

SAGE Publications / (c) The Author(s)

VERSION

AM (Accepted Manuscript)

\section{PUBLISHER STATEMENT}

This work is made available according to the conditions of the Creative Commons Attribution-NonCommercialNoDerivatives 4.0 International (CC BY-NC-ND 4.0) licence. Full details of this licence are available at: https://creativecommons.org/licenses/by-nc-nd/4.0/

\section{LICENCE}

CC BY-NC-ND 4.0

\section{REPOSITORY RECORD}

Creaser, Claire, and Valerie C.L. Spezi. 2019. "Improving Perceptions of Value to Teaching and Research Staff: The Next Challenge for Academic Libraries”. figshare. https://hdl.handle.net/2134/18152. 
Original Article

\title{
Title
}

Improving perceptions of value to teaching and research staff: the next challenge for academic libraries

\begin{abstract}
This article investigates the value, and perceptions of value, of academic libraries to teaching and research staff by examining working relationships between libraries and academic departments in universities.
\end{abstract}

Eight case studies were undertaken in the US, the UK and Scandinavia. Primary findings were analysed and triangulated with a series of short surveys to ascertain whether they resonated with other librarians' experiences.

The article offers examples of good practice in the area of partnership building for academic libraries to improve their value to, or perceptions of value by, teaching and research staff, as well as raise their profile and better market their services to this category of users. Those examples may be of interest to fellow library practitioners and researchers interested in exploring further library-faculty interaction and collaboration. 


\section{Keywords}

Academic libraries; value; teaching staff; research staff; LIS-faculty partnerships

\section{Introduction}

At times of economic stringency, demonstrating value to institutional stakeholders has become an increasingly important activity in academic libraries around the world. The need to demonstrate value is far from being novel; academic libraries have been dealing with the issue for many years, especially value to students - not only in response to student fee models in place, but also because libraries genuinely want to offer a good service to their community of users. Academic libraries collect wide-ranging statistics, and have developed, over time, a vast array of indicators enabling them to demonstrate evidence of their value to the student community.

This article reports on the findings of a 6-month research project which took a global perspective on the issue of library value, focussing on the relationships between academic libraries and academic departments. The aim of the project was to explore the value of academic libraries for teaching and research staff. The objective was to identify examples of good practice from which other institutions could learn in respect of the support librarians provide for teaching 
and research staff, and the working relationships between academic libraries and academic departments.

\section{Background}

The value of libraries, particularly academic libraries, has become an important topic in the library sector, focussed on the demonstration of value to various institutional stakeholders, and some excellent summaries have been published (e.g. Oakleaf, 2010). In the area of value for research, a study on the use of ejournals and their value to UK higher education institutions indicated that research performance was strongly positively correlated with high levels of per capita library expenditure and use of e-journals (RIN, 2011).There is evidence to suggest that libraries and librarians are not recognised as information resource providers in the research context, as they strive to make access to those resources as seamless as possible for individual researchers (RIN \& RLUK, 2011). In a UK study of scholarly readings and value of library resources, it was found that success is closely linked to the number of readings done by faculty; that journal articles provide most of the substantive information that is incorporated in the creation of new knowledge (research process); and that the library is the primary source for article readings (Tenopir \& Volentine, 2012). Less evidence is available regarding the value of academic libraries in teaching, 
although the Library Impact Data Project ${ }^{1}$ in the UK is one example, looking at the link between student library use and attainment. Information literacy instruction is part of this process and is often regarded as one of the most important ways - albeit indirect - that librarians support teaching staff, along with activities such as processing of reading lists, creation of subject guides etc.

Libraries are changing. Whereas librarians were once closely associated with their library building, this is no longer the case. With the advent of instant seamless and networked access to electronic resources and services, libraries are no longer defined by their walls and the work of librarians has changed as a consequence. The underlying issue is that the extent of such change has not always permeated all levels within the higher education sphere, thus affecting perceptions of value. As librarians are becoming ever more successful in providing seamless remote access to resources and services, there is a growing disconnection between librarians and academics, particularly researchers (RIN \&RLUK, 2011). With academics and university senior managers showing inertial and traditional perceptions, one of the main challenges for libraries and librarians today revolves around communication. Libraries and librarians must engage with members of academic staff to let

\footnotetext{
${ }^{1}$ http://www.jisc.ac.uk/whatwedo/programmes/inf11/activitydata/libraryimpact.aspx
} 
them know how libraries have changed to meet changing information needs (RIN \&RLUK, 2011).

New roles for librarians, particularly in support of the process of scholarship, are emerging from the academic library nebula, and librarians need new skills particularly in research support (Auckland, 2012). With the rapid development of electronic resources and services, combined with the emergence of a usercentric culture, libraries and librarians have tried to embed themselves into teaching and research environments better to serve their users, through more appropriate design and delivery of library services (Kesselman \& Watstein, 2009). By doing so, librarians have created new roles for themselves particularly in the areas of integrated information literacy instruction and scholarly communication. In a way, the 'embedded librarian', as described by Kesselman \& Watstein (2009), has been the precursor of the partnership culture we see emerging today.

The creation and development of partnerships with academic departments and individual members of teaching and research staff is a key element of the change taking place in the sector. Libraries are encouraged, and expected, to develop this new area, as reflected by the inclusion of the development of librarian-faculty partnerships in the Association of Research Librarian's (ARL's) strategic plan for 2010-2012 (ARL, 2009). Information literacy instruction 
provides great opportunities for librarians to develop teaching partnerships with faculty through the provision of embedded information literacy courses. In his seminal work, Hardesty (1991) was already advocating that the best way to provide information literacy instruction to students was for librarians to work together with faculty. However, it is also recognised that partnership building with faculty may present some difficulties. This is the result of a variety of factors, including different work cultures (Mounce, 2010; Hardesty, 1995), and different perceptions and understanding of the role of librarians. While if librarians have long recognised the need for information literacy instruction, this recognition has arguably yet to take place within higher education in general (Weetman Da Costa, 2010). Although there is evidence that faculty value information literacy skills (Gullikson, 2006; Saunders, 2012), it is legitimate to question whether they have a good understanding of what information literacy is and how to achieve information literacy outcomes. Faculty think the term is too vague and confusing (Gullikson, 2006) and their perceptions of information literacy are often limited to retrieval and access aspects, or simply confused with IT literacy (Saunders, 2012). There are differences in the way disciplines value the various skill elements of information literacy (Weetman Da Costa, 2010; Saunders, 2012). There is evidence of a gap between the type of information literacy skills and competencies that teaching staff want their 
students to have, and the skills actually supported and developed in courses taught by those staff (Weetman Da Costa ,2010). The better understanding faculty have of information literacy standards, the more this gap is likely to be reduced, although faculty tend to have a fragmented approach to information literacy instruction, calling upon the librarian for ad-hoc sessions (Saunders, 2012). Librarians have traditionally taken ownership of the teaching of information literacy skills - although the issue of how, when and by whom such skills should be taught does not yield a consensus amongst faculty - and if they wish to embed further information literacy into the curriculum, they need to engage and communicate with faculty (Saunders, 2012). An underlying issue in information literacy teaching is the very perception librarians have of this role as an integral part of the job or as an extra duty - and how well they are formally prepared for this task during their training (Bewick and Corrall, 2010; Julien and Genuis, 2011), which may indirectly impact on faculty perception and teaching partnership opportunities. Embedded information literacy instruction is far from being the norm in higher education institutions, and is often perceived as confined to certain disciplines, such as health and medical sciences. In his literature review of faculty-librarian teaching collaborations for information literacy instruction (which essentially focuses on US examples), Mounce (2010) shows that embedded information literacy instruction is not confined to a 
specific group of disciplines but is spread across broad subject areas (Sciences; Social and Behavioural Sciences; and Humanities) - albeit unevenly within those areas. In the Sciences, Biology and Nursing come first in terms of embedded teaching of information literacy; in the Social and Behavioural Sciences, it is Business and Education; while in the Humanities, it is English composition.

Less evidence is available about the creation and development of research partnerships with faculty, which may include grant proposal writing, collaborative research, research data support and management. The current emphasis on open science and data sharing has put data management and curation at the forefront of these new roles for librarians, although libraries are not necessarily regarded by faculty as the first point of contact for their data problems (Gabridge, 2009).

One important element in the literature about partnerships is that communication between librarians and teaching and research staff is paramount, to foster mutual understanding and the creation of partnerships. It is sometimes argued that communication can be hindered by the different status staff have within the institution. In the US, it is quite common to see librarians having faculty status alongside teaching and research staff. This can help both in developing stronger librarian-faculty relationships, as librarians are seen by 
faculty as their peers, and in influencing policy through a library voice on various university governing committees (Bodrero Hoggan, 2003). The way academic libraries present themselves to faculty determines the nature of their relationships. The library has traditionally enjoyed a central place in campus life, but its position within the institution had remained in essence that of a service provider, shaping faculty perceptions over many years. With more emphasis being placed on collaboration and partnership, such a position is no longer tenable. A culture of collaboration and partnership requires the partners to be on equal footing and recognised as such, i.e. each party contributing expertise and knowledge. This is why the image the library projects to its constituencies is important. While communication is an essential component of partnership building, other elements, such as having a sound understanding and identification of faculty needs, also impact on library-faculty relationships, particularly in terms of building trust and changing perceptions (Amante et al., 2012).For instance, at Cornell College Library, an image of specialised expertise was achieved through a clear and outward-facing redefinition of librarians' roles and position titles, which helped foster collaboration with faculty (Donham \& Green, 2004). 


\section{Methodology}

The project aimed to explore the value to and impact of academic libraries on teaching and research staff in three broad geographical areas: the United States of America, the United Kingdom and Scandinavia. During the course of the research, considerable interest was expressed from elsewhere, and this paper includes analysis of data from the rest of the world.

The research was carried out in two phases. A series of eight case studies was undertaken between January and May 2012 to investigate and identify examples of good practice - four in the US, two in the UK and two in Scandinavia. Each case study included interviews with two librarians, two members of the teaching and research staff, and a representative of the senior management of the university. Potential case study volunteers were invited to come forward via posts on various library-related mailing lists; the research team also sought suggestions from the information professional community. The selected case studies, which included both research intensive and teaching intensive institutions, were:

- USA: Purdue University; Towson University; University of Utah; Wake Forest University.

- UK: University of Nottingham; University of Sussex 
- Scandinavia: Karolinska Institutet (Sweden); Oslo and Akerhus University College (Norway)

The initial findings from the case studies were analysed and triangulated, via a series of online surveys, to ascertain whether the case study experiences and issues were typical of the wider sector. A series of short surveys was sent out in May 2012 to relevant library mailing lists in the three target regions, as well as to personal contacts and information professionals who had expressed an interest in the project and offered to help distribute the survey more widely. A total of 786 responses were received: 326 from the US, 237 from the UK, 67 from Scandinavian countries, and 156 from librarians in other parts of the world. As the numbers of responses from the Scandinavian countries and the rest of the world were low, these regions were combined in the quantitative analyses, to give greater validity to comparisons.

The survey data were analysed using the SPSS ${ }^{\circledR}$ software package. Although the methodology did not produce a random sample of respondents, it was felt important to identify potential differences between the regions which might warrant further investigation. The $\mathrm{X}^{2}$ statistic was used, differences have been noted where this had a significance level of $5 \%$ or better. 


\section{Findings}

Showing value, and improving perceptions of value, for the library service as a whole depends on the detail of the services offered, and how those services are delivered. All eight case study institutions offered a core set of support services for teaching and research staff. Some variations were noted in the extent to which those support services were actively developed and promoted.

Differences may be attributable, among other things, to the nature of the institution (teaching or research-lead institution), the staff capacity available at the library and the capability of the library to identify the needs of the teaching and research staff community and to keep pace with the evolving nature of those needs. This section summarises the main services academic libraries provide for teaching and research staff, with a particular focus on innovative and value added approaches to support services that yield good results in terms of faculty buy-in and engagement with the library and librarians.

\section{Support for teaching staff}

The librarians interviewed considered that the main support for teaching staff was provided indirectly, via support for students' learning. A core set of teaching support services emerged, however, and included the delivery of information literacy training in various forms; the production of print and/or electronic subject guides; the management of reading lists; the management of resources budgets; 
the development and care of the library's collections; the promotion of newly acquired resources; and activities based on liaison work with academic departments/schools. The survey asked librarians how important they felt each of these services were in their library, and which was most valued by teaching and research staff.

Only 41 librarians (5\% of respondents) reported that their library did not teach information literacy embedded in departmental courses, and $92 \%$ of respondents who offered the service rated it as important or very important. This service was ranked top of the list in terms of perceived value to teaching staff, in all three areas (Figure 1).

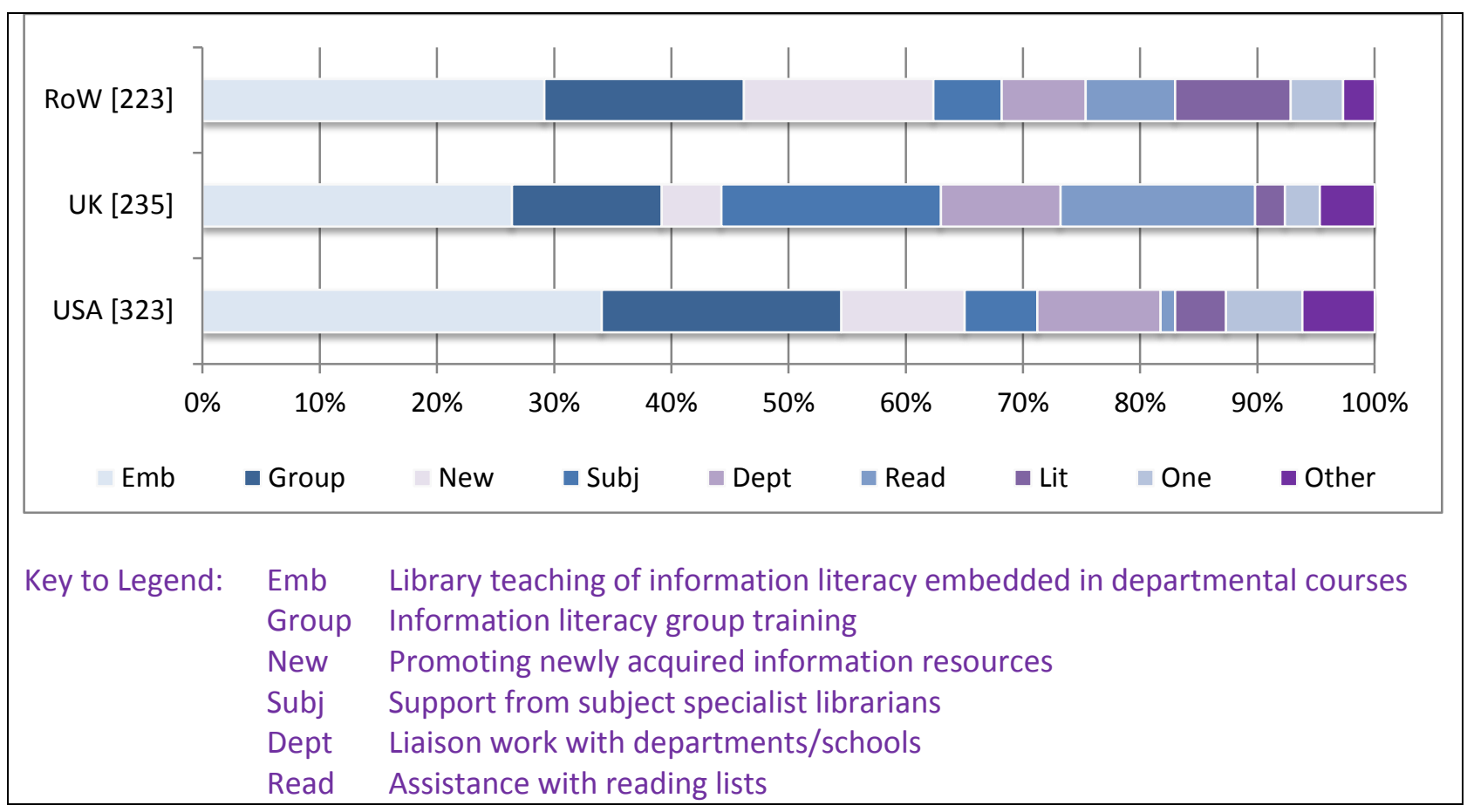




\begin{tabular}{|ll|}
\hline Lit & Help with literature searching \\
One & $\begin{array}{l}\text { One-to-one information literacy training } \\
\text { Other }\end{array}$ \\
& $\begin{array}{l}\text { Copyright clearance for course material; Bibliometric analysis; Support for } \\
\text { open access publishing }\end{array}$ \\
\hline
\end{tabular}

Figure 1. Which service do librarians think is most valued by teaching staff. ${ }^{2}$ (Total numbers of respondents given in square brackets)

One-to-one information literacy training was provided by $98 \%$ of respondents' libraries, and considered important or very important by $88 \%$ of respondents whose libraries offered it, overall. Group training was offered slightly less frequently than one-to-one training, but still only $4 \%$ of respondents said that their library did not offer it. Again, there was no difference apparent between countries in how the importance of such training was perceived, with $90 \%$ of librarians where it was offered considering it to be important or very important. Perhaps more interestingly, 3\% of respondents considered such training to be unimportant in their library.

There were interesting country differences in the assistance offered with reading lists, with such support reported more frequently from the UK than in the US or the rest of the world, and more likely to be considered important (Figure 2). Given the relatively low importance attached to this service by US respondents, it is not surprising that this option was not frequently perceived as being the most valued service by teaching staff there, ranking ninth in the list of

${ }^{2} x^{2}=110.5 ; 16 d f ; p<0.001$ 
twelve services included. In the UK, it came third, after embedded library teaching and support from subject librarians (Figure 1).

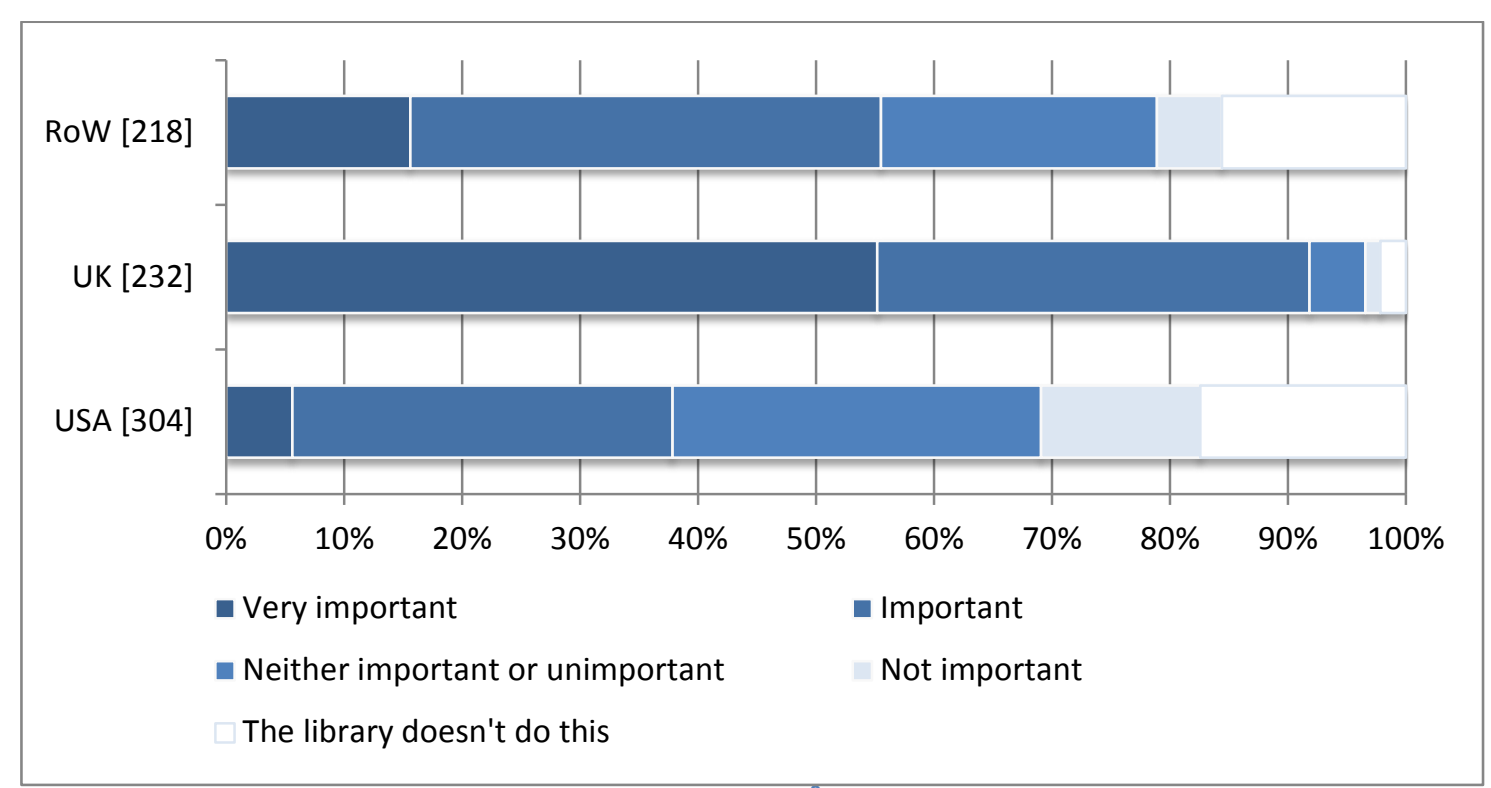

Figure 2. Importance of assistance with reading lists. ${ }^{3}$ (Total numbers of respondents given in square brackets)

Only 15 respondents indicated that their library did not promote newly acquired information resources. Overall, 94\% of respondents who offered the service felt that it was important or very important in their library. Respondents from the rest of the world were more likely to select this service as being the most valuable to teaching staff than those in the UK or US. In the UK, it ranked only sixth in the list, compared to third in the US and the rest of the world (Figure 1)

${ }^{3} x^{2}=207.5 ; 6 \mathrm{df} ; p<0.001$ 


\section{Services in support of research}

Research support for faculty was noticeably less developed and structured than teaching support. Two main reasons were put forward by the librarians interviewed. On the one hand, librarians lacked confidence to approach academics, who were described as projecting a 'self-sufficient' image, to offer their assistance in research; they did not know how to articulate the help they could offer in terms that resonated directly with research staff's interests. One US librarian thought that 'the real issue is getting faculty to recognise that they need our assistance.' On the other hand, it was recognised by most of the librarians interviewed that research support tended to be sacrificed to accommodate the demands of the students' learning experience. The extent to which research was supported at each institution varied greatly, but research support services generally included literature searching, help with open access publishing, help with self-archiving in the institution's open access repository, and bibliometric services. These topics were included in the survey, which asked librarians how important they felt each of these services were in their library, and which was most valued by teaching and research staff.

Literature searching is one of the more traditional services provided by librarians, although it had diminished in importance with the advent of userfriendly electronic databases, which researchers could use for themselves. The 
explosion of information online, and in multiple versions, in recent years has brought librarians' skills in this area back into vogue, and help with literature searching was available in $97 \%$ of respondents' libraries. Although all countries offered this equally, respondents in the US gave slightly lower importance ratings $\left(x^{2}=10.4 ; 4 d f ; p<0.05\right)$. Overall, $89 \%$ of respondents rated this activity as important or very important in their library. Literature searching was ranked top in the list of services thought to be most valued by research staff in all three areas (Figure 3). 


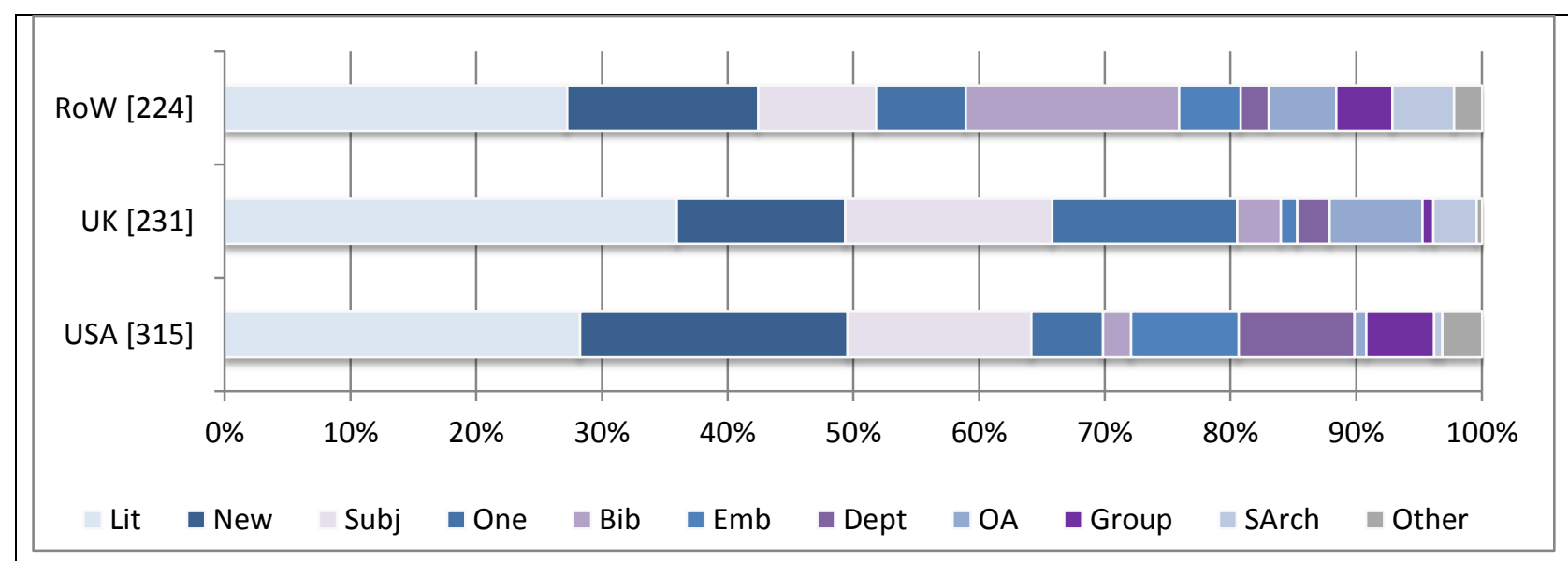

Key to Legend: Lit Help with literature searching

New Promoting newly acquired information resources

Subj Support from subject specialist librarians

One One-to-one information literacy training

Bib Bibliometric analysis

Emb Library teaching of information literacy embedded in departmental courses

Dept Liaison work with departments/schools

OA Support for open access publishing

Group Information literacy group training

SArch Support for self-archiving

Other Assistance with reading lists; Copyright clearance for course material

Figure 3. Services thought to be most valued by research staff. ${ }^{4}$ (Total numbers of respondents given in square brackets)

Library support for open access publishing was more likely to be available, and given greater importance, outside the US and UK (Figure 4). Respondents from the US were least likely to consider this service to be the most valued by their research staff, with only $1 \%$ choosing this option (Figure 3 ), placing it $11^{\text {th }}$ of the twelve services (only support for self-archiving was lower). This compares to $7 \%$ of respondents in the UK, and 5\% in the rest of the world selecting this option.

${ }^{4} x^{2}=139.9 ; 20 d f ; p<0.001$ 


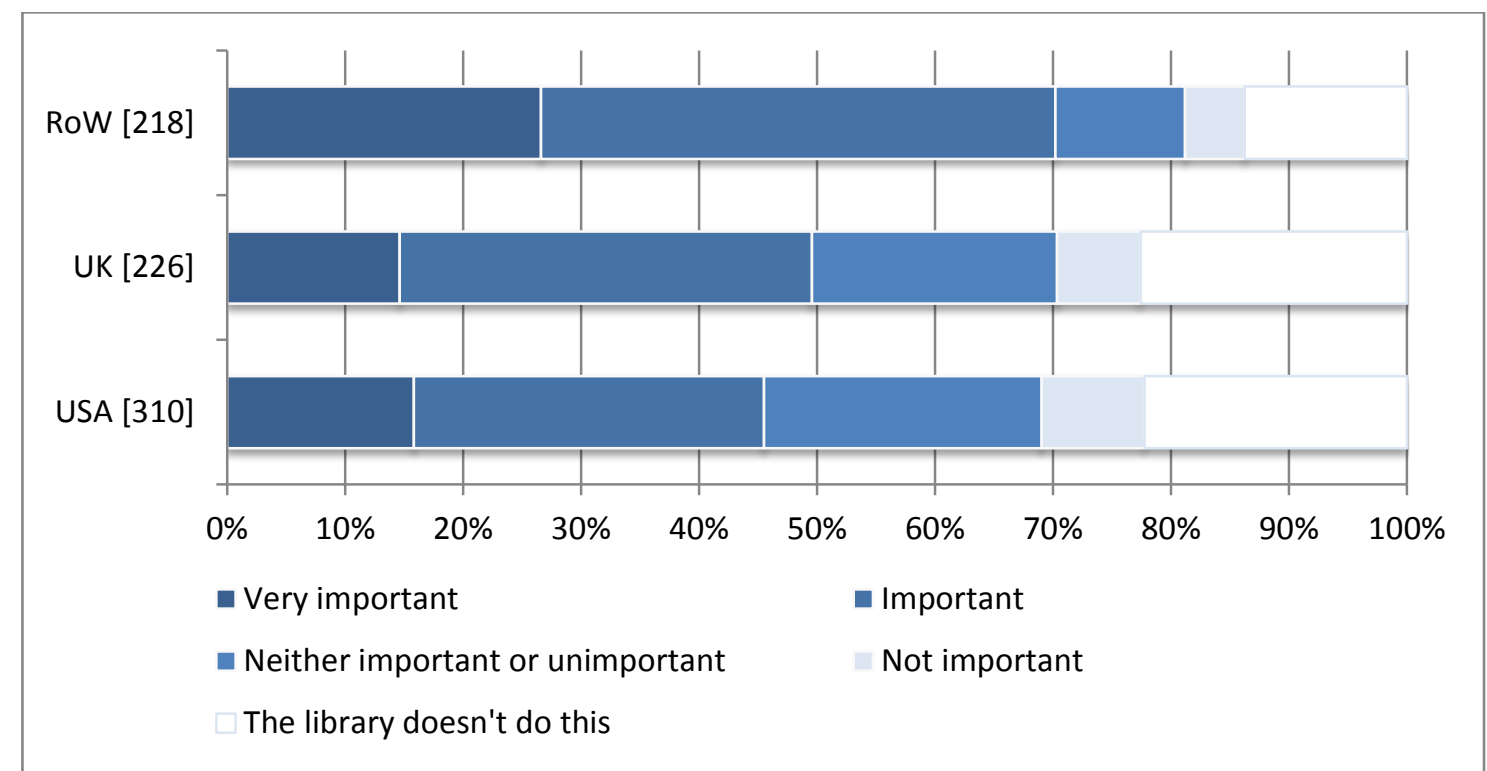

Figure 4. Importance of support for open access publishing. ${ }^{5}$ (Total numbers of respondents given in square brackets)

Again, country differences in the support available for self-archiving were marked, with similar patterns to those for open access publishing support. Librarians in the US were least likely to report that their library offered support for self-archiving, and rated its importance below their counterparts in the UK, who in turn rated this below librarians in the rest of the world (Figure 5). Given the current levels of interest in institutional repositories, in the context of both open access to research outputs and the increased visibility of that research, the proportion of librarians reporting that their library did not support selfarchiving was perhaps surprising.

${ }^{5} x^{2}=28.7 ; 6 d f ; p<0.001$ 


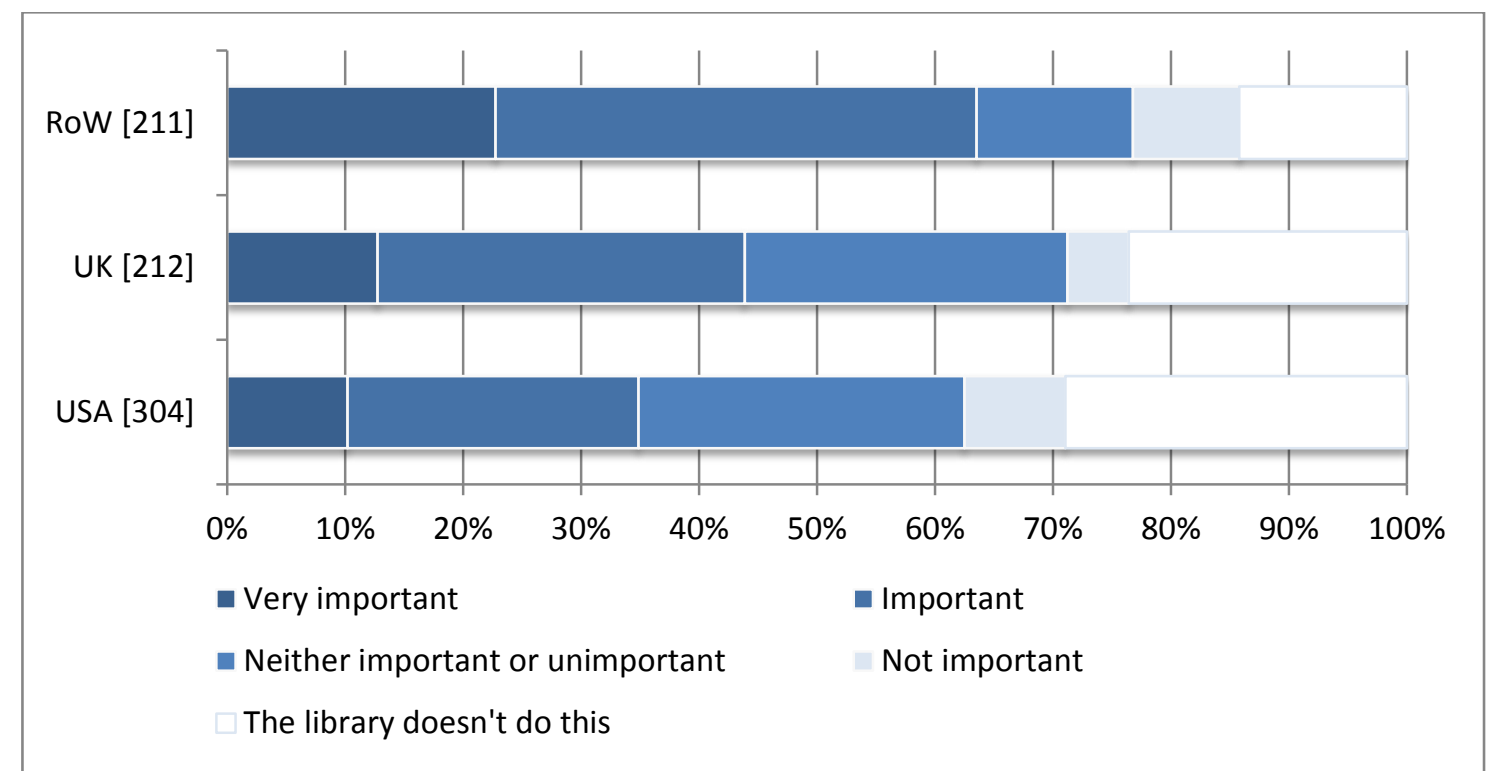

Figure 5. Importance of support for self-archiving ${ }^{6}$ (Total numbers of respondents given in square brackets)

Overall, $8 \%$ of respondents did not know whether their library offered bibliometric analysis services. There were clear country differences, both in the importance of this service, and the likelihood that it was available (Figure 6). Where it was available, it was the service which received the lowest importance rating overall. This service was considered to be the most valued by research staff by $17 \%$ of respondents in the rest of the world countries, placing it second in their ranking (Figure 3). In contrast, just $2 \%$ of US librarians, and $3 \%$ of UK respondents considered it to be the most valued by research staff. Bibliometrics and open access services are one of the manifestations of the changing role of librarians. The notable difference in the rating of these services between the UK

${ }^{6} x^{2}=34.8 ; 6 \mathrm{df} ; p<0.001$ 
and US on the one hand, and RoW on the other hand, may reflect the high value placed on such services in Scandinavian countries, particularly in Sweden (Åström and Hansson, 2012) - almost one third of the RoW group in our analysis is from Scandinavia.

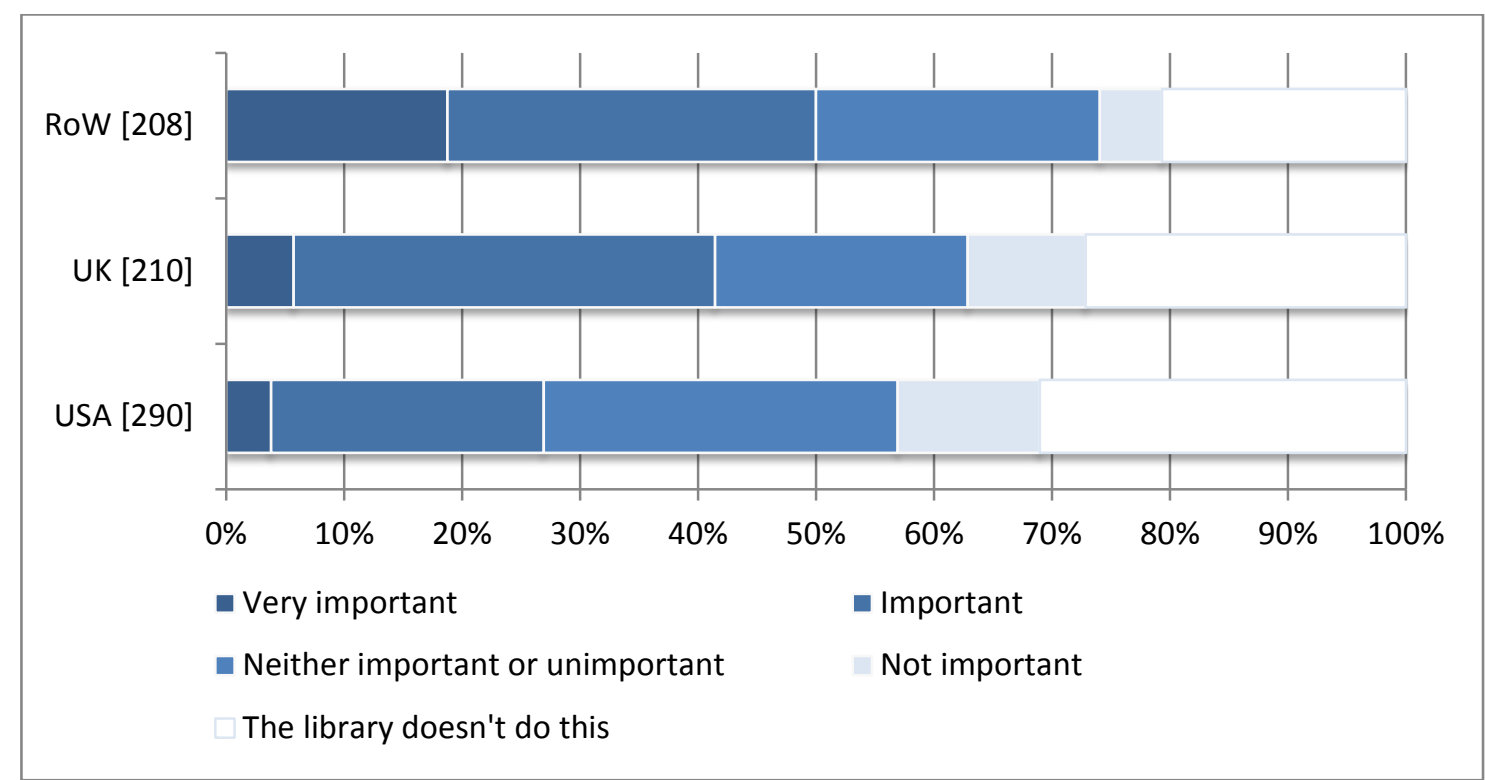

Figure 6. Perception of the importance of bibliometric analysis services. ${ }^{7}$ (Total numbers of respondents given in square brackets)

\section{Offering value-added services for the teaching and research staff}

\section{community}

Some institutions provided services that are usually regarded as being outside the normal remit of libraries. At the University of Utah, the library provides teaching staff with a video production suite that they can use to create teaching content. The libraries at the Karolinska Institutet and Wake Forest University ${ }^{7} x^{2}=48.0 ; 6 \mathrm{df} ; \mathrm{p}<0.001$ 
provide information technology tools for teaching staff, and help them to use and incorporate tools, such as podcasts, wikis or websites/blogs, in their courses. Purdue University has taken a pro-active approach to research support, identifying research data management as an area that should be developed and supported by the library.

Our case studies featured outstanding examples of partnership building with members of the teaching and research community. Although not all institutions were able to offer appropriate levels of collaboration at the time of our study, a vision of teaching and research partnerships with faculty was nevertheless in the minds of the librarians/library managers, and case study libraries were keen to move in this direction. However, staff capacity, poor communication and relationships with departments/schools, and with individual staff, as well as perceptions of value of the academic library by teaching and research staff were found to be stumbling blocks.

A particular issue in the US case studies was the status of librarians, and how they were perceived by faculty members. Some librarians felt that faculty did not want outside help for their research; they considered themselves as experts in their field, relied on their research network for help, and did not see librarians as a natural first point of contact to resolve problems. This was described as an important barrier making it difficult for librarians to approach faculty to offer help 
in teaching and research. In this respect, US librarians that had faculty status were unanimous in the view that this made a difference to the way they interacted with faculty, helping them to be regarded as 'full' partners when collaborating with faculty, and allowing them to work on grant proposals. One librarian commented that having faculty status 'eliminates the potential challenge of asking the question: is that something a librarian should be doing?' For another librarian, faculty status helped to shift perceptions: 'if faculty see us as equals then they might see us as people who could be worth consulting rather than as a sort of service entity.'

\section{Teaching partnerships: embedded information literacy teaching and co-}

\section{teaching}

All case study institutions had embraced the concept of teaching partnerships, and were positioned somewhere along the spectrum of integrated teaching, from embedded teaching to co-teaching. This was an area that librarians were particularly keen to develop, and all case study libraries were working on providing some forms of integrated teaching of information literacy and research skills. Faculty interviewed in the case studies indicated that, although they could see the benefits of embedded information literacy skills training, they had reservations about co-teaching, owing to the time and level of collaboration required to make it successful. 
The University of Nottingham offered an excellent example of integrated teaching. Embedded library interventions were very successful, particularly in medicine and the health sciences, which have a long tradition of close collaboration with subject librarians in relation to their evidence-based practice. Driven by national changes to nursing education, requiring all nurses to be educated to degree level, the University developed a new course, with a high level of blended learning, in close collaboration with the library. The library was involved from the outset, over an 18-month development cycle, identifying relevant resources and developing information skills elements for the course. Early involvement enabled librarians to show academics how they can have an input, and complement the academics' work, so that students develop skills and become competent practitioners at the end of the course. Critical thinking workshops use examples from the literature to illustrate the argument, and the library brings in a wide range of nursing resources for students to evaluate, using their skills as a nurse. This directly supports the academic curriculum and links with academic outcomes. Sessions are highly interactive, delivered jointly by library and subject specialist staff. There are direct benefits to the departments involved - academics see the value of what librarians provide and the impact this has on the quality of the work they receive from students. Embedding librarians' instruction into modules also helps increase formal 
contact hours for students - this is an important driver as students demand more for their fees. Previous ad-hoc information skills teaching did not count towards this.

Building on the success of this collaboration, the library has recently taken a pro-active approach to promoting integrated teaching to other disciplines, starting with a trial in the Classics department, to gauge the extent to which such teaching partnerships were achievable in disciplines that did not have an inherent evidence-based approach. The success of the trial has led to significantly increased demand for such intervention.

Two important points were made by librarians at Nottingham regarding the introduction of embedded information skills instruction. First, for the library, this represents a culture shift from reacting to ad-hoc requests from departments to provide library teaching interventions to a more pro-active approach to embedded library intervention. Secondly, the Arts librarians had already established a very good relationship with the Classics department, which showed openness, interest and enthusiasm towards working with the subject/liaison librarian to deliver essential information and research skills.

Co-teaching, whereby the librarian not only provides information skills instruction but also contributes fully to the design, content, assignment and 
delivery of the course in collaboration with subject staff, represents the extreme end of the teaching partnership spectrum. In the US, both Purdue University Library and the University of Utah Library were engaged in co-teaching in some disciplines. The partnership between the librarian and the member of teaching staff is such that each partner contributes to the same extent, on the basis that each partner fully recognises and values the contribution of the other and that each one's role is defined and agreed beforehand. As with embedded teaching, co-teaching partnerships often start in medicine and health sciences, where strong relationships are established with librarians owing to the influence of the Cochrane collaboration and the strong evidence based approach in those disciplines. There was evidence that this is changing, albeit slowly, and trickling down to other academic departments. One librarian at the University of Utah felt that co-teaching was spreading to disciplines that had incorporated the evidence based approach in their research methodology, such as social work. Another participating librarian reported that she had recently co-taught a class on food policy and nutrition.

The development of co-teaching activities by librarians is rather new in the library sector, and is described by one of the librarians interviewed as 'not quite the norm yet.' It was felt that one major issue with co-teaching, and to a certain extent with embedded teaching, was the difficulty in scaling it up, owing to the 
amount of work required for every single teaching partnership. Librarians did not always feel this could be scalable across an entire department, let alone the whole institution.

\section{Research partnerships: grant proposals, research data management and}

\section{systematic reviews}

Research partnerships, in the form of collaborative research or collaboration in the writing of grant proposals, were an area of research support that libraries were particularly keen to develop, described as a new and developing trend. Librarians involved wished to see this field of activity expanding in the future, although our interviews with faculty indicated that such library initiatives were not necessarily welcomed, and some research staff expressed reservations about the development of any research partnerships with librarians.

Researchers can have strong views and exhibit territorial behaviours about what research is and who does research, and seemed to struggle to understand the nature of the librarians' contribution.

The University of Nottingham and Purdue University both reported having been involved in preparing grant proposals in collaboration with research staff. Positioning was key to the approach taken by both libraries, where the librarians were seen by the researchers as "bringing something different to the table." 
At Purdue University - a science and technology-oriented university - librarians have a strong track record of research partnerships with faculty. Their success relies on a very pro-active approach to understanding the data needs of researchers, and a substantial amount of groundwork was undertaken by the library. This led to the creation of a data specialist services librarian position, whose role is to help research staff to get more value from their data through the organisation, description, dissemination (in ways that feel appropriate to research staff), and preservation of data. This data service allowed Purdue Library to set up a significant number of research partnerships, particularly to secure grants, with 68 members of research staff in 31 departments on 95 grant proposals between 2005 and 2010. The librarians' main contribution is to ensure that grant proposals are supported by sound data management and curation plans, which are increasingly required by funding agencies as part of any submission.

The approach adopted at Purdue University is successful because of the way the service is framed: presented from a researcher perspective rather than from a library perspective. This means that the service is tailored to individual data needs, rather than being a generic data curation training, and researchers see it as an individual response to their very specific needs. Engagement and interaction between the librarian and research staff are thus facilitated. 
Although the approach may be perceived as very time-consuming, with associated scale-up issues, the library believes that this is worthwhile, as it enables the library to build trust and credibility among researchers, and ultimately build a reputation as a valuable partner in the research process.

Another outstanding research partnership was found at the University of Nottingham, where the library had successfully established research partnerships in the area of medicine and health sciences with the involvement of subject librarians in systematic reviews. For this, the librarians' time is costed, and documented as part of the research proposal at a high level, to develop robust search strategies. The expertise of subject librarians in systematic reviews is recognised by research staff, who are willing to pay for librarians to conduct the systematic literature search, and include them as co-authors on the publications. Other case study institutions had mentioned occasional help with systematic reviews, but the University of Nottingham had taken this a step further to develop a full research partnership over and above the standard research support.

The outcome for the library in such research partnerships is to build a reputation, and show research staff that the library has much to offer in terms of research support. The challenge is to change perceptions and bring the various constituencies to recognise that the library and librarians can help in novel ways. 


\section{Communication}

Personal relationships and communications with teaching and research staff, as well as the marketing of library services, have a big impact on both levels of use and perceptions of value. All librarians interviewed indicated the importance of communication and personal relationships with individual faculty members and departments, and the difference these can make to perceptions of value of the library. One commented, 'we sometimes misjudge why the relationships aren't there; $[\ldots]$ a lot of time we assume the faculty that aren't approaching us are doing that because they don't need us,... and it may be that they just don't know that we can help them with the particular thing that they're doing.' In the survey, the most important means of communication with teaching and research staff was thought to be building personal relationships, with $97 \%$ of respondents saying that this was important or very important in their library; only two respondents reported that their library did not do this.

Personal relationships were developed in various ways. A library presence at academic meetings was valuable in bringing librarians and teaching staff closer, opening up communication channels between the two parties and enabling librarians to show teaching staff how they can help. Informal encounters, holding office hours in the department, and attendance at various events taking place on campus were also deemed to help develop communication and build 
relationships. A physical presence in the department, however slight, was perceived as helping to increase visibility; one librarian commented 'I think the best way is to be in their face' while another said 'if the liaison [librarian] doesn't make it clear to [faculty] that they are available for consulting, teaching [...] they would be ignored.' At Towson University, one liaison librarian was extremely pro-active in building personal relationships with her faculty. She actively sought out faculty members at events and conferences taking place on campus, used social media such as her own Facebook page to develop personal relationships, and organised events such as panel discussions for books published by faculty members in the presence of the author, in order to showcase the work of faculty.

Results from the survey reinforced these findings. Informal encounters were thought important or very important by $94 \%$ of all respondents whose libraries did this. There was a clear difference between the US and UK, and the rest of the world, however (Figure 7). 


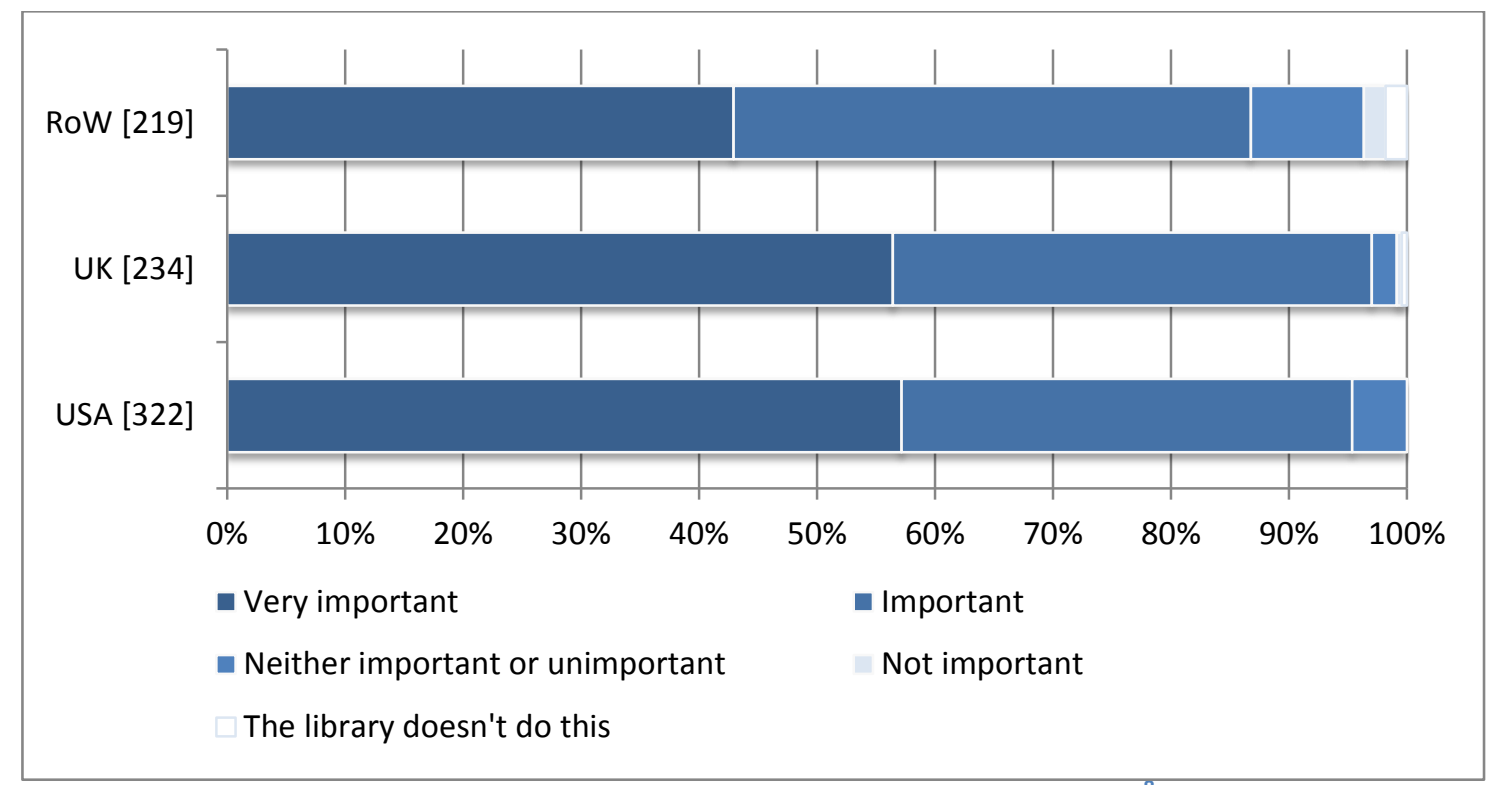

Figure 7. Importance of informal encounters as a means of communicaiton. ${ }^{8}$ (Total numbers of respondents given in square brackets)

Participation in academic meetings, such as departmental meetings, was seen as an enabler for establishing new lines of communication and developing personal relationships with faculty, a way to promote how the library and librarians can help academic staff in their teaching and research activities, and a way to identify current needs. It was clear from the interviews that librarians felt communication should take place at various levels within the institution. Meetings between senior library managers and those in other parts of the institution, including academic departments, were perceived as important to develop an understanding of the role of the library within the institution at a higher managerial level. Attendance at school or departmental meetings is a

${ }^{8} x^{2}=23.3 ; 4 d f ; p<0.001$ 
communication strategy used more widely, and considered to be more important, by respondents in the UK than those in the US or the rest of the world (Figure 8). Overall, $7 \%$ of librarians in the survey said that their library did not do this; this drops to just $2 \%$ in the UK, where only one librarian thought that it was not important. It was felt that communication with a department was generally facilitated if the leadership (Dean, Head of Department/School) was supportive.

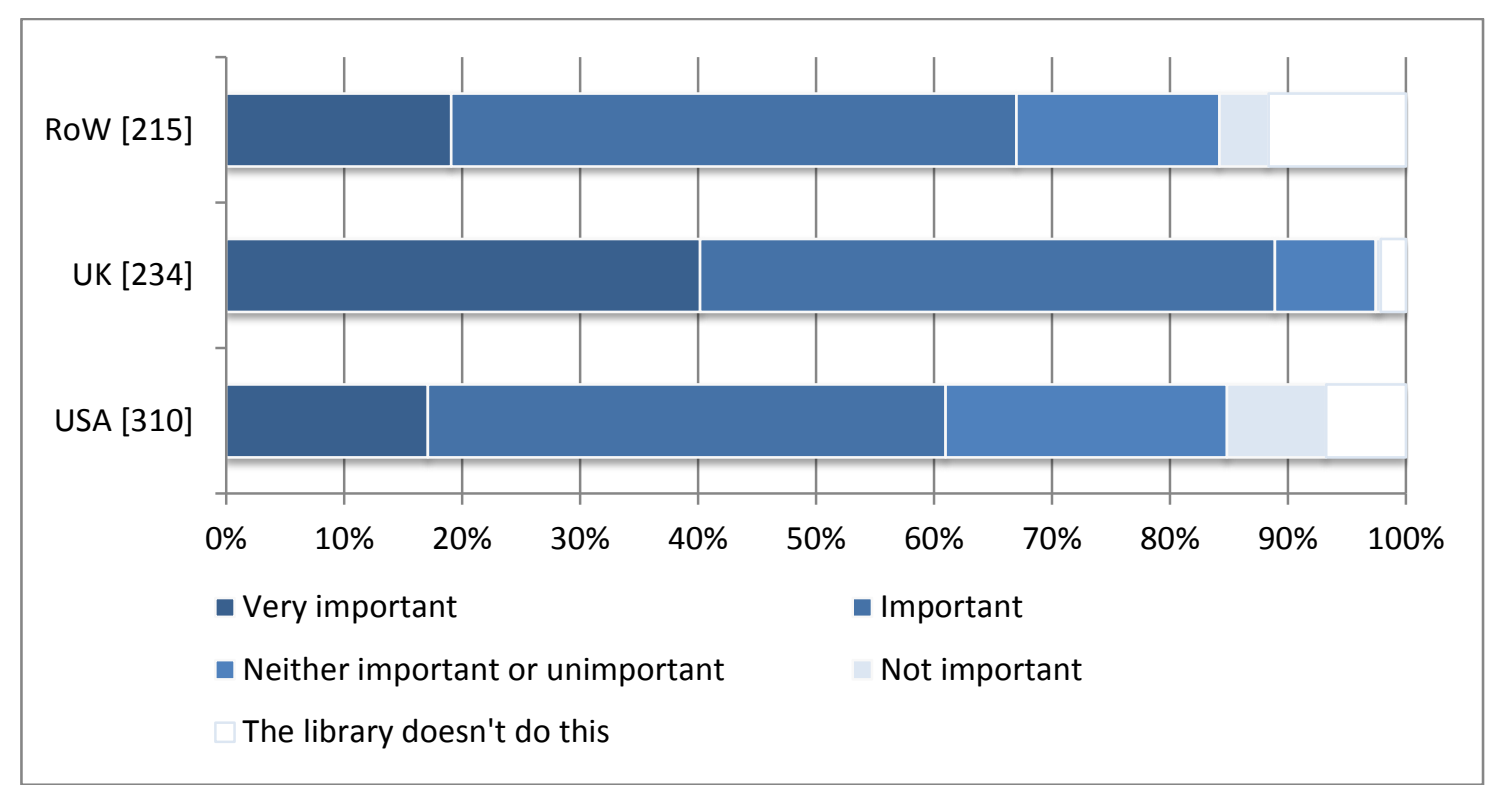

Figure 8. Importance of school/departmental meetings as a means of communication. ${ }^{9}$ (Total numbers of respondents given in square brackets)

The librarians interviewed also felt they were not always very good at asking faculty for feedback about how they felt the library was meeting their teaching and research needs. One librarian commented 'sometimes we don't ask

${ }^{9} x^{2}=66.7 ; 6 \mathrm{df} ; p<0.001$ 
because we are afraid of the answer', expressing a fear that faculty could develop expectations that cannot subsequently be met owing to resourcing or capacity issues.

The case studies had indicated that the most appropriate method of communication would be different depending on the message which was being conveyed, so in the survey we asked librarians which of a variety of communication and marketing methods, from traditional reporting to use of social media tools, they thought were the most effective for four different types of message.

Web 2.0 and social networking tools generally were not widely used, and not considered to be of great significance in library marketing and communications. Librarians in the UK were most likely to report that their library used a blog, with those from the rest of the world countries most likely to rate their blog as very important for library communications (Figure 9). Library Facebook pages were more likely to be used by respondents in the US than those in the UK or rest of the world. As with library blogs, respondents from the rest of the world countries were more likely to consider this to be an important means of communication (Figure 10). UK respondents were more likely to use Twitter than those in the US or the rest of the world, but did not rate it as being particularly important for communication and marketing (Figure 11). 


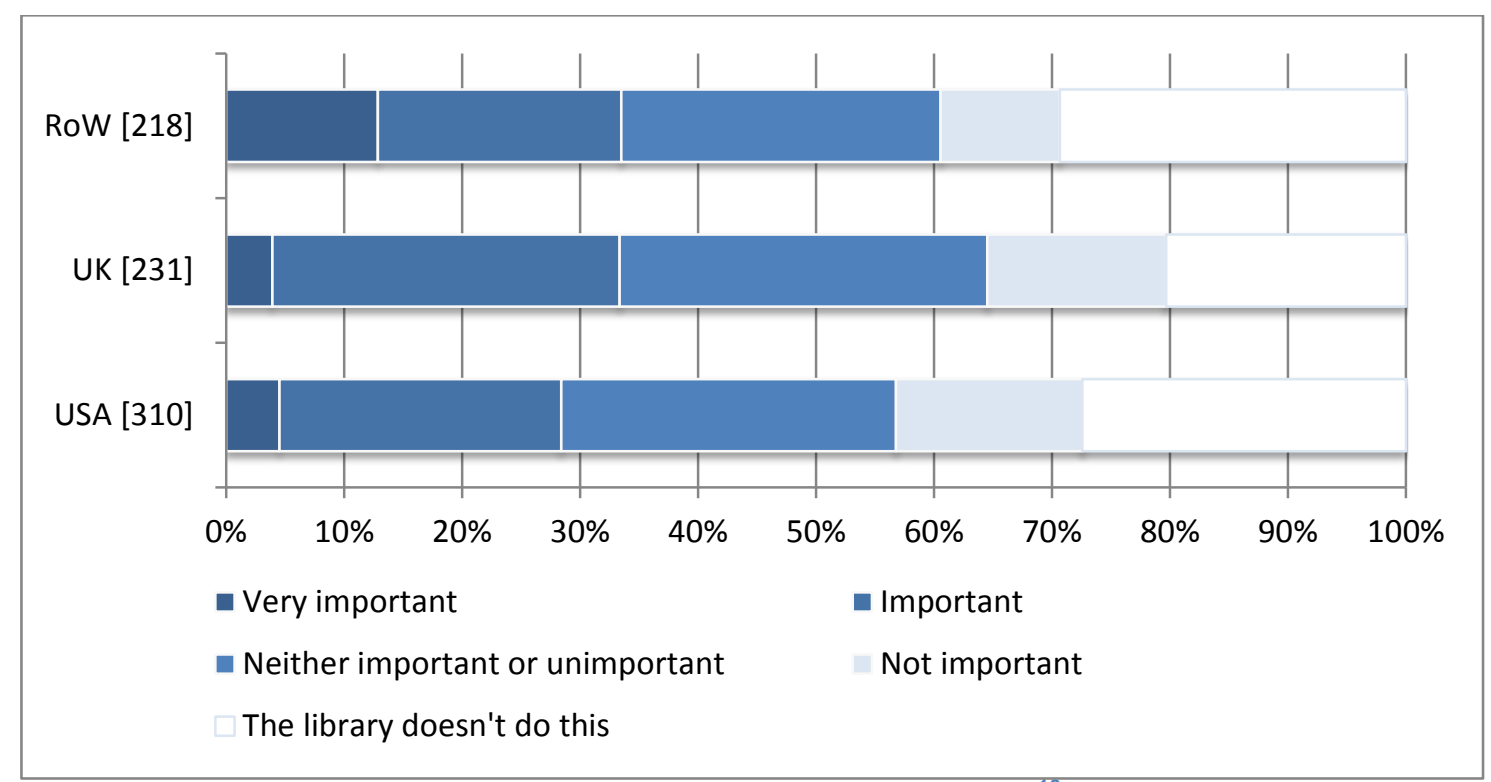

Figure 9. Importance of a library blog as a means of communication. ${ }^{10}$ (Total numbers of respondents given in square brackets)

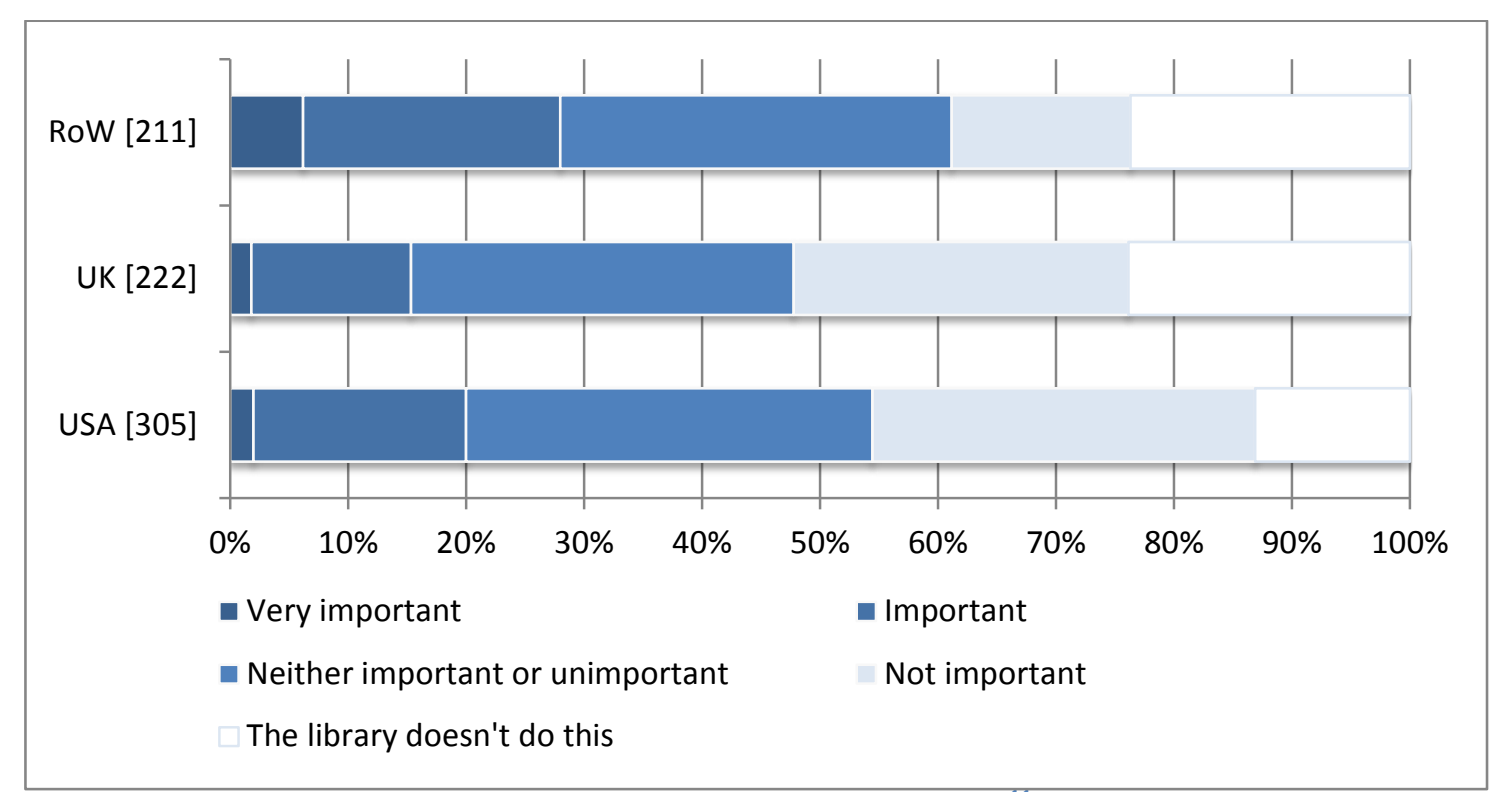

Figure 10. Importance of Facebook as a means of communication.. ${ }^{11}$ (Total numbers of respondents given in square brackets)

${ }_{11}^{10} x^{2}=26.0 ; 8 d f ; p<0.005$

${ }^{11} \mathrm{X}^{2}=22.6 ; 8 \mathrm{df} ; \mathrm{p}<0.005$ 


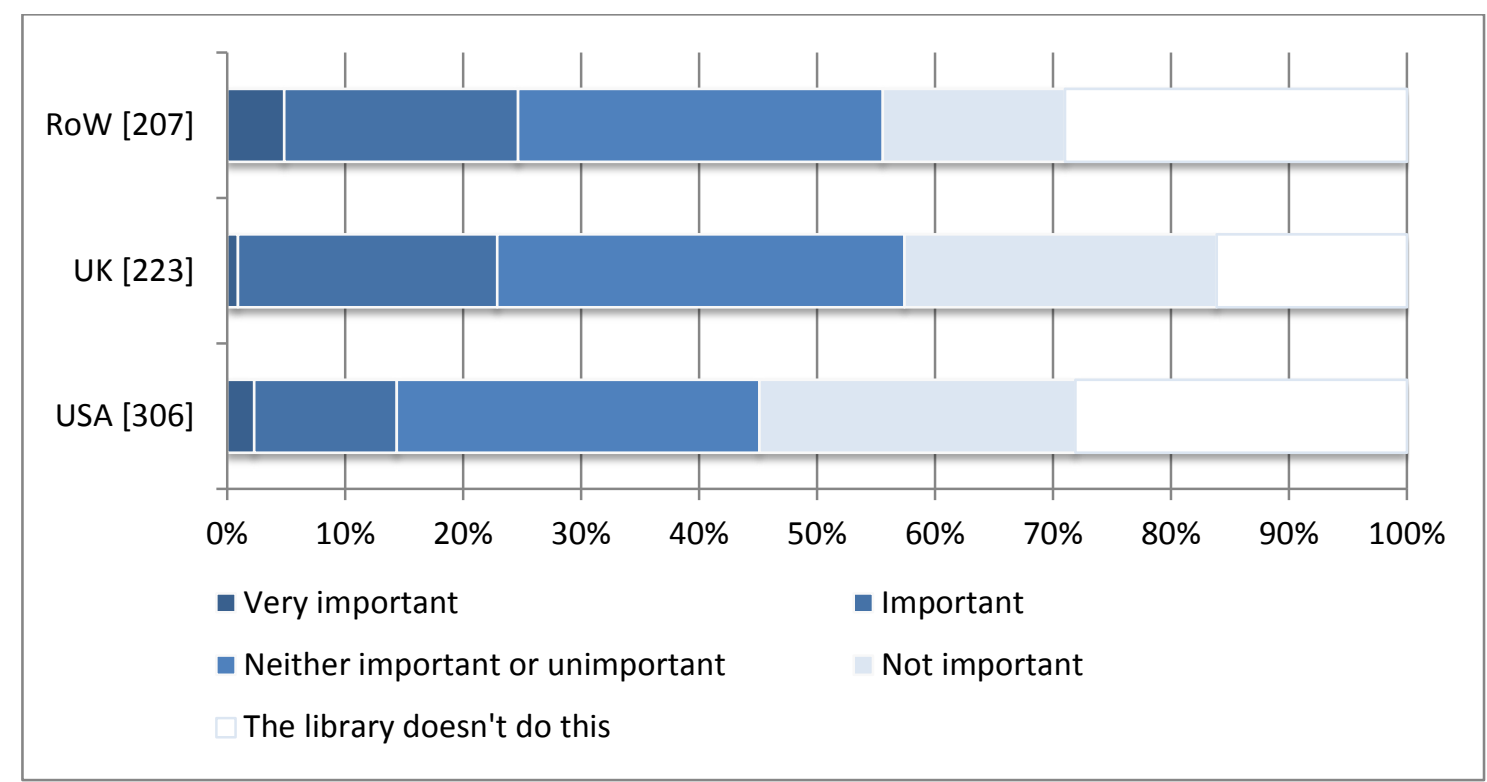

Figure 11. Importance of Twitter as a means of communication. ${ }^{12}$ (Total numbers of respondents given in square brackets)

Bulk emails might be seen as one of the more traditional ways for libraries to communicate and market their services, and just $4 \%$ of respondents said that their library did not do this. However, they are not viewed as a key tool where they are used, with only half of these respondents rating them as either important (43\%) or very important (7\%). A further $12 \%$ overall thought that such communications were not important to their library. This contrasts with the general perception that such emails were the most effective way to communicate general library announcements, with $38 \%$ of librarians choosing this option overall. They were also the second choice for promoting trials of new

${ }^{12} x^{2}=20.9 ; 6 d f ; p<0.005$ 
information resources in all three regions (Figure 12), and most popular for announcing new services and resources (Figure 13).

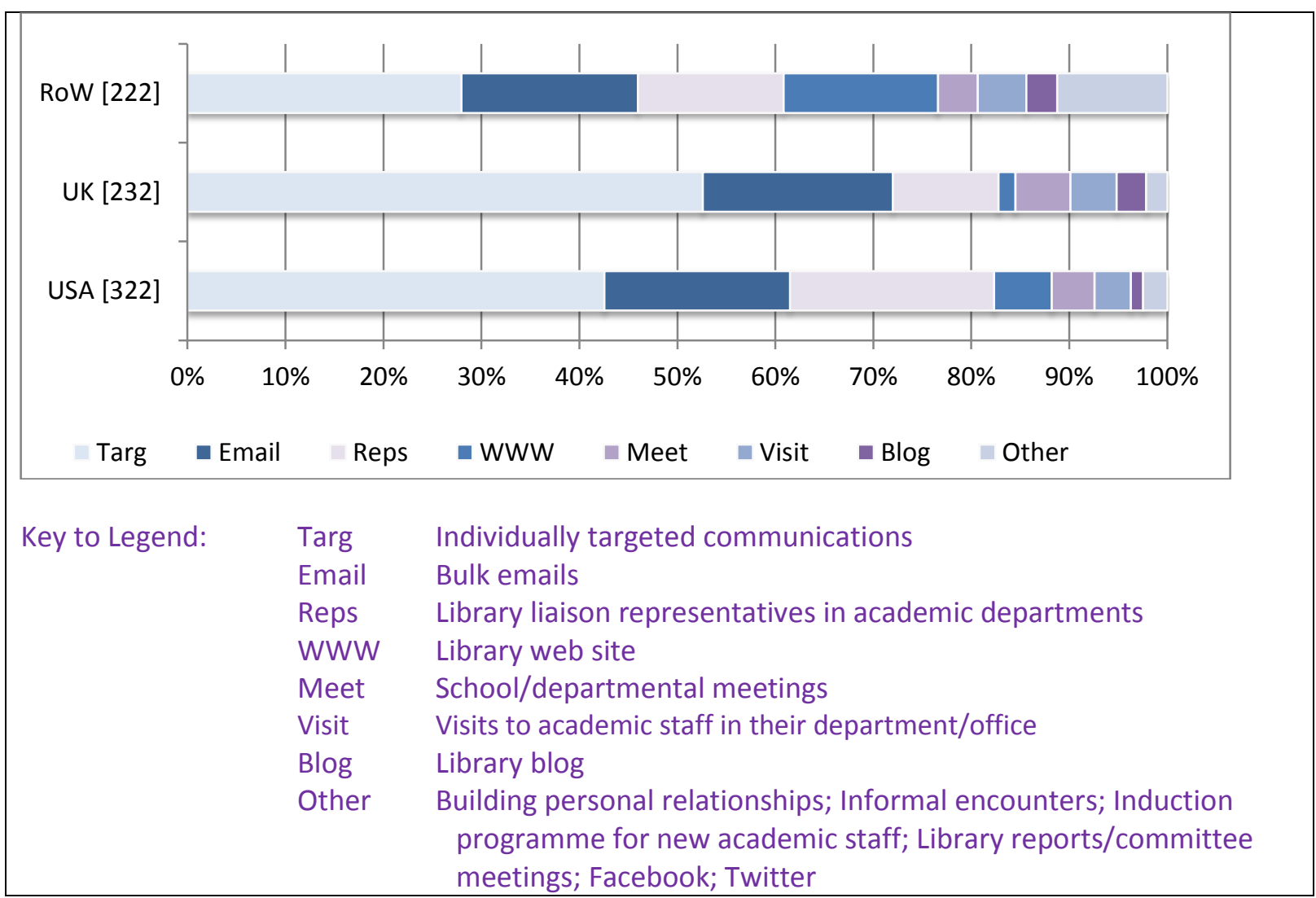

Figure 12. Most effective communication channel for promoting trials for potential new information resources. ${ }^{13}$ (Total numbers of respondents given in square brackets)

The website was thought to be the most effective means of communicating

general library announcements by $27 \%$ of respondents, the second most

popular choice for this purpose in all areas. Library liaison representatives

${ }^{13} x^{2}=87.2 ; 14 d f ; p<0.001$ 
ranked third in the list of effective methods for communicating general library announcements, selected by $10 \%$ of respondents overall.

Librarians in the rest of the world countries also considered the website to be effective in announcing new resources and services, with $25 \%$ selecting this option - more than any other. Respondents from the UK were more likely than those in the US or rest of the world countries to consider departmental meetings to be an effective channel for announcing new resources and services, with $17 \%$ selecting this, making it the $3^{\text {rd }}$ most popular option for this purpose in the UK (Figure 13). 


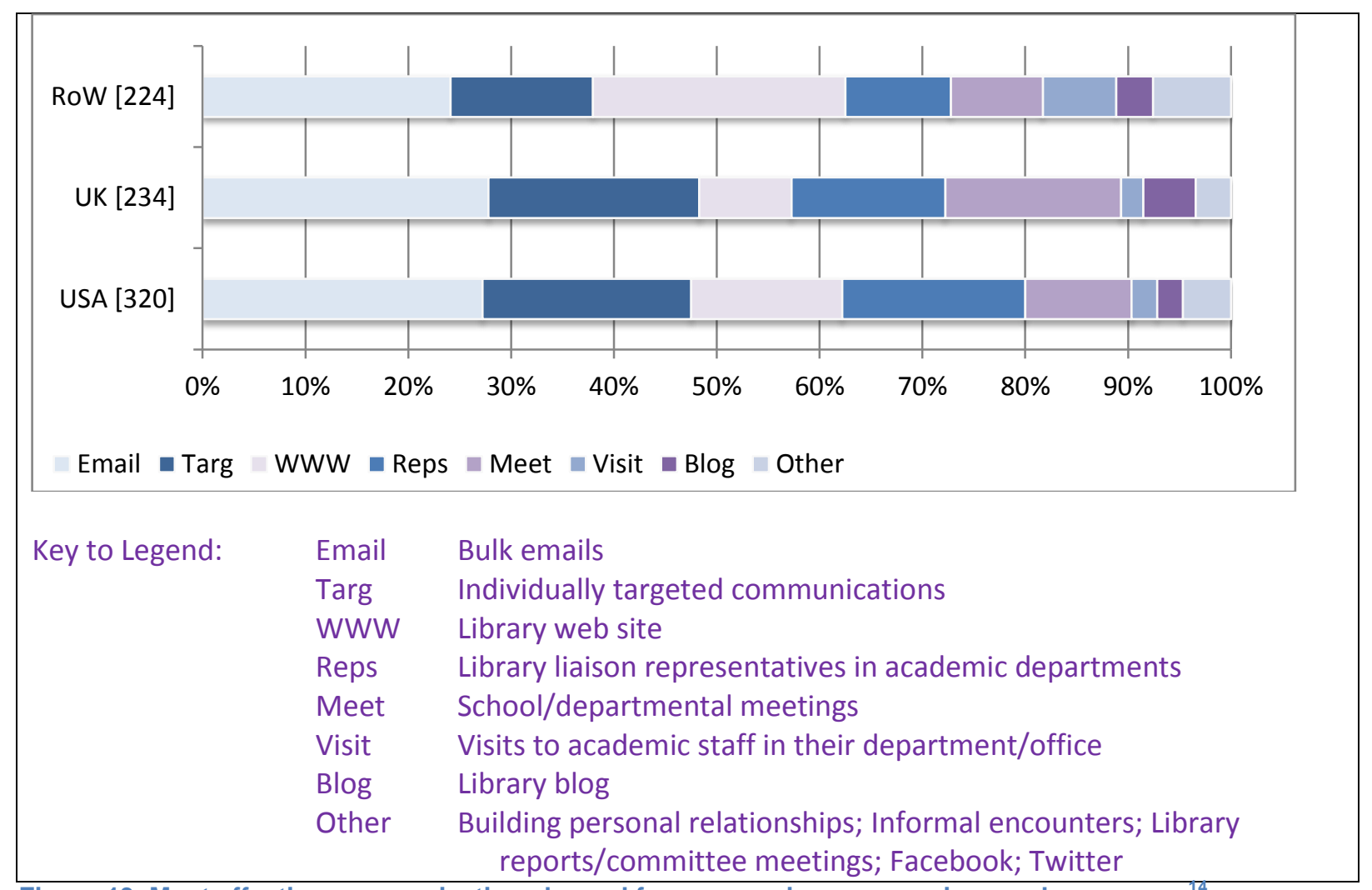

Figure 13. Most effective communication channel for announcing new services and resources. ${ }^{14}$ (Total numbers of respondents given in square brackets)

Individually targeted communications were thought to be the most effective means of promoting trials of new information resources in all three areas, but particularly in the UK. Librarians in the rest of the world countries considered the website an effective means of promoting trials of new information resources, with $16 \%$ selecting this option, compare to $6 \%$ of US respondents and $2 \%$ of UK respondents (Figure 12).

${ }^{14} x^{2}=51.7 ; 14 d f ; p<0.001$ 
There was little consensus between respondents on the most effective communication channels for promoting and marketing existing services and support (Figure 14). There were differences apparent between countries - US respondents appeared to favour using library liaison representatives in academic departments (22\%) followed by individually targeted communications (15\%). In the UK, the library website and school or departmental meetings were each selected by $16 \%$ of respondents, with library liaison representatives chosen by $15 \%$. In the rest of the world, the library website appeared to be the preferred option, chosen by $21 \%$ of respondents, with $14 \%$ opting for individually targeted communications. 


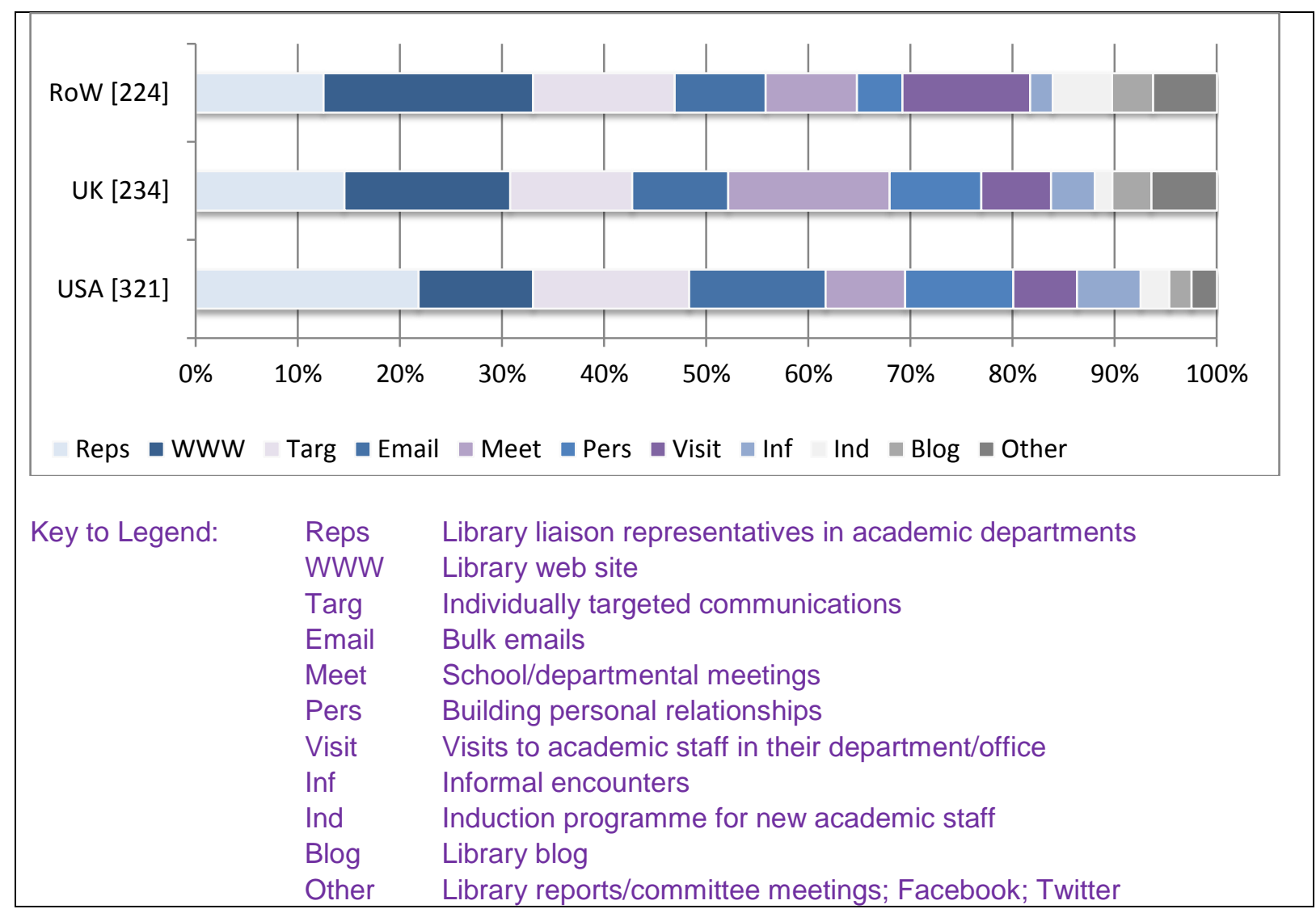

Figure 14. Most effective communication channel for promoting/marketing existing services and support. ${ }^{15}$ (Total numbers of respondents given in square brackets)

\section{Discussion}

Elusive value to faculty - evidence of vallue and perceptions of value

Demonstrating value to teaching and research staff is a challenging issue, as

current metrics and the variety of data collected - mainly focussed on usage -

do not always seem appropriate to measure the real value of the academic

${ }^{15} x^{2}=60.5 ; 20 d f ; p<0.001$ 
library to members of teaching and research staff. Institutions are aware of the need to collect data about faculty satisfaction, but the quantitative analysis of use of services, which is the backbone of most, if not all, analyses of the evidence of value to students, is not necessarily seen as a satisfactory way for measuring value to academic staff - although some of our case study libraries collected this type of data for lack of anything better. No processes are currently in place to enable them to collect evidence about faculty satisfaction. Librarians are waiting for guidance in two areas: collecting evidence of value and increasing faculty perceptions of value. The LibValue project ${ }^{16}$ has brought some interesting results in measuring evidence of value, mainly based on the concept of Return On Investment (ROI). From the outset, our research was motivated by a different approach to value, geared towards providing libraries with examples of good practice to increase value and faculty perceptions of value.

The difficulty with the concept of value to faculty is that it is elusive. There is little evidence of the extent to which current teaching and research support services are actually valued, because individual libraries do not capture this evidence in a systematic way. However, it is possible to use perceptions of value, i.e. how well librarians and faculty feel the library is meeting the needs of

\footnotetext{
${ }^{16}$ http://libvalue.cci.utk.edu/
} 
teaching and research staff, as a proxy for the value of academic libraries. This is done through a sound examination of libraries' provision of teaching and research support services available to faculty. Findings from our case studies suggest that, overall, the library is well perceived by members of the teaching and research staff community, although some of the faculty members interviewed acknowledged that their views were probably not representative of colleagues in their department. One interviewee offered the bold view that faculty sometimes lacked consideration, displaying 'a condescending attitude towards librarians', which may be symptomatic of the lack of understanding of the work librarians do to help faculty in their teaching and research. This in turn comes back to communication and marketing of services.

Our research indicated that librarians generally find it difficult to articulate the support they provide for teaching and research staff, beyond their traditional remit of providing access to resources. Teaching support for faculty was mainly perceived indirectly via support for students' learning, with information literacy at its core. Research support offered to faculty was significantly less developed than teaching support, which is consistent with the fact that there appears to be less evidence of librarians' engagement in research support in the literature. Various reasons were suggested for this, but librarians' lack of confidence to approach faculty to offer help, lack of understanding of researchers' needs, and 
seeing faculty as 'self-sufficient' in research, appear to be key barriers. The case study interviews suggested that research support for faculty was essentially geared towards open access and bibliometrics, and help with literature searching was not much in demand. The survey responses seemed to indicate otherwise, with help with literature searching rated as more important than open access issues and bibliometrics. The salient point to take away from these findings is that librarians do not appear to know how to articulate their research support, nor whether it meets the needs of research staff adequately.

Librarians' roles are changing and with change comes adjustment and uncertainty. With more emphasis being placed on faculty satisfaction than ever before, librarians are working on redefining their roles in terms of teaching and research support, hence their difficulty to articulate their offer.

\section{A vision for the future: working in partnership with faculty}

Libraries are trying to move away from their sole service provider function, wishing to be seen as teaching and research partners, with more involvement in the curriculum and in the research activity of the institution. There were clear indications from the interviews with library managers that teaching and research partnerships are the way forward, and this strategy is part of the repositioning of the library on campus. 
Working in partnership with faculty is a concept that has gained attention in the academic library sector in recent years, evidenced by the ARL's strategic plan for 2010-12 (ARL, 2009), although such collaborations were in place before they were formally referred to as 'partnerships'. In response to the many changes that have impacted the academic library sector in the last decade, librarians have re-invented themselves and created new roles, which are part of a culture shift at sector level whereby librarians are looking at embedding themselves into teaching and research environments (Kesselman and Watstein, 2009) rather than responding to ad-hoc requests from faculty.

Findings from our research indicate that Kesselman and Watstein's 'embedded librarian' is more of an aspiration than a reality, although librarians are becoming more involved in embedded information literacy instruction, particularly in the health sciences. Not all institutions offer teaching partnerships, however, and for those which do, it is down to the individual librarians to make it happen and engage with faculty. As a result, levels of collaboration vary greatly, not only from one institution to another, but also within the same institution. We found no evidence of processes in place to facilitate the creation of partnerships, which depend on the personal relationships librarians have established with faculty members, and faculty's open-mindedness towards such collaboration. 
Research partnerships are seen as even more difficult to establish. They require librarians to take on new roles and skills enabling them to engage with faculty about their own research, and librarians do not always feel comfortable or confident to do this. Faculty do not always welcome such moves either, failing to see how the librarian can contribute to their research, and may view such initiatives more as competition than support - someone encroaching on their own area of expertise. Research Data Management (RDM) is an example of research partnership in higher education institutions, and is often presented as an emerging area in which librarians potentially have a major role to play. RDM requires librarians to acquire a set of new and technical skills, become familiar with RDM stakeholders and refine their understanding of researchers' creation, use and re-use of data (Cox et al., 2012).

\section{A push for communication to realise the vision of partnership working}

\section{with faculty}

Communication, including liaison work with departments and individual faculty members, was found to be paramount to fend off traditional - and possibly now obsolete - views of academic libraries. The difficulty lies in getting the message across about what the modern academic library is about, and how librarians can help faculty in their teaching and research through the provision and delivery of teaching and research partnerships. With instant and remote access to 
resources and services, libraries have fallen off faculty's radar. There is evidence in our research that faculty do not always know how to utilise library services and librarians' expertise, despite the various communication channels libraries use to reach out to faculty. This issue of a growing disconnection between academic libraries and faculty resonates with findings from the RIN \& RLUK study (2011). In this context, partnership working between librarians and faculty is even more foreign to faculty's understanding of the role of the library on campus. Librarians have re-invented themselves, developed new skills and created new roles, but faculty are not always aware of these changes. The research showed that the modern academic library is a hub of a diverse and specialised expertise, and faculty should take advantage of this pool of skills and expertise. The research also highlighted that a lot more work is needed in terms of communication and marketing to change perceptions, and bring faculty to think of the library beyond the traditional tasks of reference and collection care and development.

Communication (at all levels) with faculty is essential to move teaching and research support services forward, allowing librarians to get a greater insight into faculty's teaching and research needs, and thus to offer a tailored provision of support services. Librarians who were involved in partnerships with faculty thought that a greater understanding of faculty's needs was essential, and 
allowed the librarian to be recognised as contributing a specific expertise that would otherwise be missing.

As faculty have arguably grown disconnected from the library, it is essential for librarians to reconnect with faculty and let them know about the evolving role of the library and librarians on campus, and how those new roles can help faculty in their teaching and research. Building personal relationships with faculty was presented as a key element of this process. It was acknowledged that trying to connect on a personal level with individual faculty members was a particularly time-consuming task, but extremely worthwhile as it opened doors for greater interaction and collaboration.

\section{Conclusions}

The academic library sector is re-inventing itself through the provision and delivery of novel teaching and research support services. Notable examples of good practice were identified in the areas of embedded information literacy and co-teaching to support teaching staff, and in a variety of research partnerships between research staff and libraries. Building personal relationships is at the core of successful partnerships, and good communications are a key element of this. There are barriers to be overcome before such partnerships become the norm rather than the exception, including the perceptions of academic staff and 
the capacity of libraries to deliver. Communication is key to changing perceptions of value and yielding academic staff's buy-in. 


\section{Bibliography}

Amante MJ, Extremeño Al and Da Costa AF (2012) Modelling variables that contributes to faculty willingness to collaborate with librarians: The case of the University Institute of Lisbon (ISCTE-IUL), Portugal Journal of Librarianship and Information Science. Epub ahead of print 10 October 2012. DOI: $10.1177 / 0961000612457105$

ARL (2009). ARL Strategic plan 2010-2012. Available at < http://www.arl.org/bm doc/strategic-plan-2010-2012.pdf>. Accessed [08.10.2012]

Åström F and Hansson J (2012) How implementation of bibliometric practice affects the role of academic libraries Journal of Librarianship and information Science. Epub ahead of print 3 September 2012. DOI:

$10.1177 / 0961000612456867$

Auckland M (2012) Re-skilling for research. An investigation into the role and skills of subject and liaison librarians required to effectively support the evolving information needs of researchers. Report for RLUK, January.

Bewick L and Corrall S (2010) Developing librarians as teachers: A study of their pedagogical knowledge. Journal of Librarianship and Information Science 42(2): 97-110. 
Bodrero Hoggan D (2003) Faculty status for librarians in Higher Education. Portal: Libraries and the Academy 3(3): 431-445.

Cox, A, Verbaan, E. and Sen, B (2012) Upskilling liaison librarians for Research Data Management. Ariadne 70. Available at:

http://www.ariadne.ac.uk/issue70/cox-et-al (accessed 08 January 2013)

Donham J and Green CW (2004) Developing a culture of collaboration: librarian as consultant. Journal of Academic Librarianship 30(4): 314-321.

Gabridge T (2009) The last mile: liaison roles in curating Science and Engineering research data. Research Libraries Issues: a bimonthly report from ARL, CNI, and SPARC 265:15-21.

Gullikson S (2006) Faculty perceptions of ACRL's information literacy competency standards for higher education. Journal of Academic Librarianship 32(6): 583-592.

Hardesty LL (1991) Faculty and the library: the undergraduate experience. Norwood, NJ: Ablex Pub.

Hardesty LL (1995) Faculty culture and bibliographic instruction: An exploratory analysis. Library Trends 44(2): 339-367. 
Julien H and Genuis SK (2011) Librarians' experiences of the teaching role: A national survey of librarians Library \& Information Research 33: 103-111.

Kesselman MA and Watstein SB (2009) Creating opportunities: embedded librarians. Journal of Library Administration 49: 383-400.

Mounce M (2010) Working together: academic librarians and faculty collaborating to improve students' information literacy skills: a literature review 2000-2009. The Reference Librarian 51: 300-320.

Oakleaf M (2010) The value of academic libraries. A comprehensive research review and report. Report for ACRL, September.

RIN (2011) E-journals: their use, value and impact - final report. Report, Research Information Network.

RIN \& RLUK (2011) The value of libraries for research and researchers. Report, June.

Saunders L (2012) Faculty perspectives on information literacy as a student learning outcome. Journal of Academic Librarianship 38(4): 226-236.

Tenopir C and Volentine R (2012) UK scholarly reading and the value of library resources: summary results of the study conducted Spring 2011. Report for JISC Collections, February. 
Weetman Da Costa J (2010) Is there an information literacy skills gap to be bridged? An examination of faculty perceptions and activities relating to information literacy in the United States and England. College \& Research Libraries 71(3): 203-222. 